\title{
Key Concepts in Informatics: Documents
}

\author{
LÁsZló Gudenus, Henrik HelfenBein and LÁsZló ZsAKó
}

\begin{abstract}
The system of key concepts contains the most important key concepts related to the development tasks of knowledge areas and their vertical hierarchy as well as the links of basic key concepts of different knowledge areas. When you try to identify the key concepts of a field of knowledge, you should ask the following questions: Which are the concepts that are the nodes of the concept net and can be related to many other concepts? Which are the concepts that necessarily keep re-appearing in different contexts when interpreting what you have learnt before? Which are the concepts that arrange specific facts in structures, which contribute to interpreting and apprehending new information and experience? Which are the concepts that - if you are unfamiliar with and unaware of - inhibits you in systematizing various items of knowledge or sensibly utilizing them?" [8] One of the most important of these concepts is the document.
\end{abstract}

Key words and phrases: key concept, documents, informatics, primary and secondary school.

ZDM Subject Classification: Q30, Q50, Q60.

Being one of the youngest science areas and knowledge areas, informatics is difficult to define. It can be explained by its young age, and on the other hand, by its extremely fast development and its influence on several other knowledge areas.

\section{Fields of Informatics}

To define the key concepts of informatics, first you should overview the possible curricula of informatics as a field of knowledge $[5,10]$. 
A. Algorithmization, data modelling, programming (At school - and even in your everyday life - you continually execute algorithms, work with data structures e.g. fill in forms and questionnaires, design series of activities and in-formation flow processes, which implies that this world is fully comprehensible only for those who are familiar with the basics of these activities.)

B. Programming tools (They include language and other tools which you must be familiar with to be able to implement and try algorithms and data models.)

C. Performing application tasks with computer (It means the solubility of everyday problems by using IT tools: video and graphic editing, word processing, spreadsheets, database management and presentation.)

D. Managing application systems (Here you should separate the knowledge of applications from the ability to manage rapidly aging devices; although teaching how to use them, of course, should take place parallelly.)

E. Computer-aided problem solving (In this topic you should start from a problem emerged - e.g. organising a school trip. First you should approach it as an organisational task, then you should choose the tools and devices for the sub-tasks - not necessarily IT tools -, and then create a new tool if necessary.)

F. Infocommunication (You should be aware of the social impact of ICT technologies and adapt to the changes; you should use ICT tools properly.)

G. Media informatics (There appeared media heavily infiltrated with IT tools that require IT expertise for proper use; the electronic counterparts of the traditional media open up new opportunities and new media appear; all these might raise cognitive processes and entertainment to another level.)

H. Informatics tools: Principles of their operation and application (A wide variety of hardware and software tools are available, the appropriate use of which every user must acquire.)

I. The mathematical basis for informatics (The mathematical foundations necessary for IT skills are not included in the mathematics curriculum or they are not discussed where they are needed - mathematics at secondary school, for instance, does not deal with the matrix, but spreadsheet skills demand the formulation of this concept at least in an informal way - which is alright but it implies that it is the ICT subject that should discuss this issue as well as other applications of mathematics.)

J. Informatics and society (It is worth learning about the history of informatics - as it is part of the culture -, dealing with its possible development and 
its current impact on society, data security, data protection and the ethical issues of applying information technology.)

\section{Informatics competences}

The key concepts of informatics cannot be separated from informatics competences, and it is necessary that they are in harmony: $[6,11,12]$

- Algorithmic thinking

- Data modelling

- Modelling the real world

- Problem solving

- Communication skills

- Application skills

- Team work, collaboration, interoperability

- Creative skills

- Orientation and information skills

- Systemic thinking

\section{Key concepts of informatics}

The key concepts of informatics are partly based on more general concepts of other fields (e.g. sign - data are described with signs, signs are used when you communicate, and they are used to describe documents). On the other hand, these concepts appear in other subjects as well (e.g. model, problem). [7, 8, 13]

- algorithm

- data

- document

- communication

- model

- task

- problem

- project 
- program

- software

- hardware

Please remember that this overview of key concepts does not mean that it is exactly what should be taught at school. This article is about what teachers need to know so as to teach well! There are often functions related to the concepts: concepts are the ones we work with, while functions are the activities carried out on them. Consequently, it might be interesting to overview the activities.

\section{Key concepts of informatics: Documents}

The document can be defined as any traditional paper-based or electronic writing that can be created by computer. We create documents so that we ourselves or other people can see or listen to them. If we consider our disabled fellow people, documents include multimedia contents, as well, that affect several of our sensory organs parallelly. For instance feeling/fingering has a role when "reading" document written in Braille (or dot writing), just like hearing plays a part when you use screen-reader software.

Documents can be:

- text documents, traditional and electronic publications;

- diagrams, figures, photos;

- spreadsheets with data, to make calculations;

- databases to store, classify and organize data, and to prepare reports;

- presentations, electronic bulletin boards and electronic notice boards;

- video and audio documents, animations, special presentations (interactive whiteboard);

- webpages, websites;

- scores, data documents of CAD/CAM and GIS programs, (in special cases)

It is quite difficult to assign them to age-groups since students meet the very same concepts at a different age in each application. In this paper they are given at their first appearance.

From this point of view, spreadsheet and database management are interesting fields. They are first of all related to the concept of data, but calculating data 
is an algorithm, and the appearance of data is a document. This paper focuses mainly on their appearance.

Note: webpages can be regarded as documents, so the above requirements may refer to them, as well; on the other hand, they are also communication tools, so they are to be discussed in a chapter on infocommunication, too. A search on the web could result in a document, as well.

Documents can be discussed basically considering 4 aspects:

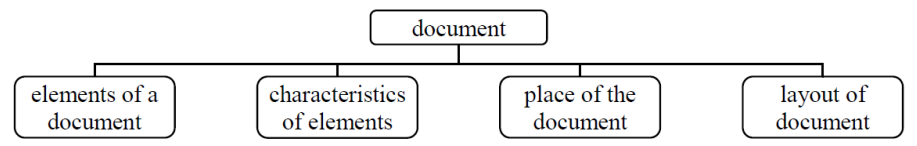

Figure 1. The aspects of examination of a document

Elements of a document can differ depending on document types. In a text document you are bound to find characters, in a drawing document you will find lines, rectangles, whereas you are higly likely to find the same elements in different documents.

You can assign features to certain elements: e.g. size or colour to visual/ visible elements; and pitch, volume etc. to audible elements (sounds).

Documents are usually stored somewhere so that others could also use them. It is often a page that you can print or watch on the screen, but it can be more interesting e.g. when the document to store contains music. On the other hand, there are documents that are kept on different sites at the same time e.g. if you have a hybrid book, you can read it on a screen or printed, and in the meantime you can listen to it being read out, with some background music being played or even you can watch a film about it.

If the elements of a document do not completely fill the place available - which is typical for visual documents - it might be interesting to see how the elements inside are laid out compared to the place and to each other.

\subsection{Areas to be developed in years $1-4$}

“... We'll teach the young freedom,

let them play, let them play.

Let the children play!"

(Attila József, translated by Peter Hargitai) 
For this age group application skill principally means video and music editing in a playful way. The first field of application - as a kind of transition from kindergarten to primary school could be the use of so-called stamping pro-grams (choosing one or more from a selection of ready-made shapes which can be easily inserted in a document - picture stamp, letter stamp).

At this level drawing includes composing a unit from simple lines and patches (colours, textures). With the help of drawings and music, coupled with some simple text or simple multimedia materials and animations can be pre-pared. Pupils can create line ornaments and mosaics. As for music applications, they can play music, make simple remakes or even compose music.

Pupils can prepare birthday invitation cards, carnival posters, classroom decorations etc. Here, of course, teacher's guidance is essential. No less important is to have a printed end-product eventually, something that pupils can take home and show their parents the work of art they have made.

Most important of all is to introduce some basic elements of documents and some document types such as drawing, text and music.

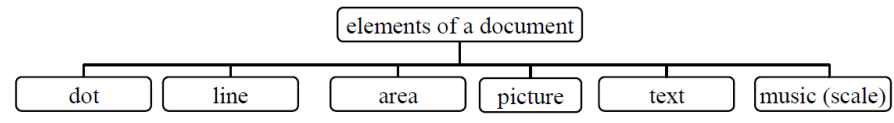

Figure 2. Elements of a document for years 1-4

As a first step, a text can be perceived as a sequence of characters, music as a sequence of sounds without any structuring. To make the simplest animation you need nothing more than a lot of sheets with drawings, e.g. fairy tale images, prepared in advance, which you can alternate at fixed intervals i.e. animation is a series of pages.

As for shapes, there are empty and filled varieties here, which is why we believe that filling in closed shapes (i.e. giving the properties of elements) may be of interest to an older age group. There are at least two types of shapes: squares and rectangles bounded by straight lines, and circles and ellipses bounded by curves.

Other irregular shape-like elements might also belong here i.e. image patterns created by others in advance or scanned images. Regarding pictures, the first necessary feature is cutting some of their parts and put them in other applications. While these patterns are often the basic elements of a "stamping" program, they can also be used in active drawing applications. 
At this stage relatively few properties of elements can only be given. Instead of specifying properties, transformations are performed: rotating, flipping or zooming.

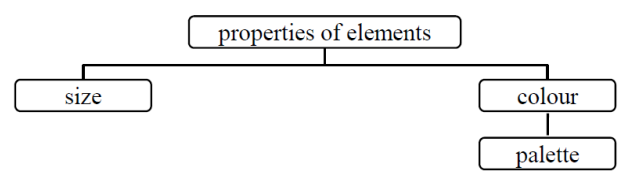

Figure 3. Features of elements in years 1-4

Documents for this age group are one page long (even if you use both sides of a sheet). The size of the page and its orientation can be different depending on the application; in addition, you can distinguish usable and non-usable areas in a page (within the margins or outside).

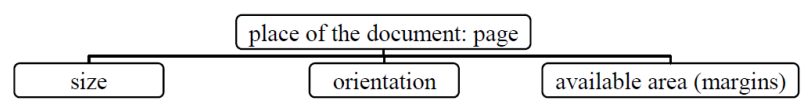

Figure 4. Place of the document in years 1-4

Regarding the lay-out of a document, let it be enough to say that the page can be freely filled with components. In contrast to text-graphic documents, "loud" documents, animations and multimedia documents are generally simpler in this respect: a piece of music goes on as long as it has sounds, and an animation will also continue until it runs out of frames.

\subsection{Areas to be developed in years 5-6}

"A game binds and unbinds. It engages. It amazes and enchants.

It is full of the two most noble features that people can notice and express: it is full of rhythm and harmony."

(Johan Huizinga, loose translation)

At this stage you can set students a target to recognize the applicability of a variety of computer tools and the improvement of already existing works. Pupils of this age should deal with graphical and text documents and knowledge about documents might come to the forefront.

The most common task types are creating, formatting, printing, storing and repairing documents that are related to students' school or home life and suit 
their fields of interest. Children of this age are still interested in playfulness, attractions and getting the experience!

They are primarily drawings, images and figures accompanied with a little text like carnival and birthday invitations, greeting cards, school or class logos, posters of various kinds, token money and playing cards. Pupils can draw plans and layouts of their classroom, the schoolyard, flats etc. If compared to the previous age group, the main difference is a bit more text in the completed documents.

If you are more concerned with the aesthetic look of pages, you may introduce some related terms including page borders, background colours and patterns. The need to use borders first may occur in page borders, and pupils might want to use not simple lines, but spectacular elements and images.

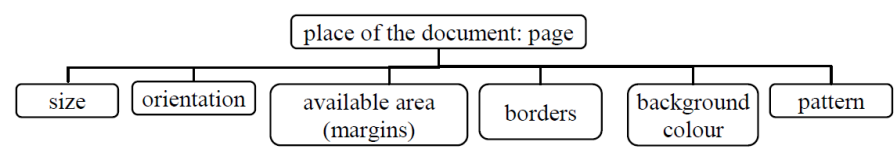

Figure 5. Place of a document in years 5-6

There appear basic document operations (creating, modifying, formatting, language functions, layout design and collecting raw material). Although due to their age characteristics, the concept of section cannot be introduced yet, orientation and setting margins and page boundaries prepare them for it.

An important novelty for students could be that elements of documents can be broken down into parts and grouped (e.g. paragraphs are made of sentences; circles and arcs can build up a human head) and these groups can be are treated together, and new operations can be introduced for them.

In a transition to sheerer text documents, it can be a good idea to insert poems: poems can be broken down to verses, then lines that you can arrange on the page in a nice way and add some illustrations. Predefined elements such as symbols, prefabricated elements, elements created by other applications can also appear in documents.

The structure of text documents:

- text - word - character

- text - sentence - word - character

- text - paragraph - sentence - word - character 
Several researchers are engaged in generalizing the elements of text documents, but they do not usually relate the refinement of elements to age groups [9]. There is also an object-oriented approach to the same issue [1].

\begin{tabular}{|c|c|c|c|c|c|c|}
\hline \multicolumn{7}{|c|}{ elements of a document } \\
\hline dot & lines & areas & texts & music (scale) & symbols & external objects \\
\hline
\end{tabular}

Figure 6. Elements of a document in years 5-6

Here the scope of properties of elements used in visible documents can significantly expand, whereas music documents should be treated cautiously, because soon you can run into professional limits; however, you can start using musical scores perhaps. After page colour, page borders and pattern now similar properties of document elements can be introduced. While for the previous age group empty and filled shapes appeared separately, at this stage filling can be regarded as a simple element property.

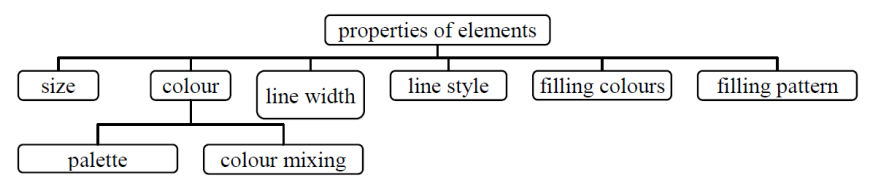

Figure 7. Features of elements in years 5-6

Regarding colours, it is the first time that you can talk about colour mixing and colour impact after choosing col-ours from the palette, of course, now without a theoretical analysis of colour-mixing models.

You should dedicate some time to discussing the properties of text elements, firstly the ones that refer to text elements themselves. Properties that are related to placing texts on a page are discussed separately. [3]

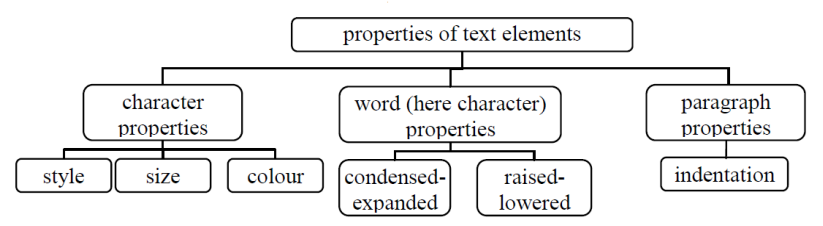

Figure 8. Properties of text elements in years 5-6 
It is not possible to format a word as a physical entity in a word processor among the usual logical units (characters, paragraphs, sections and documents) of text documents. Nevertheless, we discuss the properties of words separately, because this kind of character formatting is spectacular in character groups only.

Indenting a paragraph on the left can be done in two stages: first all lines are indented together, then the first line is treated separately.

Regarding the arrangement of elements, two methods can be applied:

- arranging the elements relative to each other (by specifying element properties)

- designing a page layout by using a table

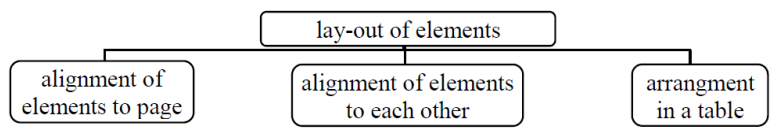

Figure 9. Arranging elements in years 5-6

As for documents, aligning to page can be alignment to the left, right, middle, or aligning to both margins by expanding elements. When aligning elements to each other, first the distance between paragraphs (space) and then the distance of a picture (or other objects) from the text appear.

When inserting a picture (or other objects) into a page, you will not meet any problems. As for texts, after introducing the concept of 'section', by adjusting margins first, you can discuss horizontal then vertical alignment.

Designing the layout of a document with many images or with more pictures and relatively little text (as compared to the amount of pictures) is a bit more complex task, and instinctive placement becomes more clumsy. Now it is time to design the page: where and what size images are to be used, and where to place the text and other items? When designing traditionally on paper, a checked notebook paper can be of use, whereas in your computer there is a more appropriate tool available: the table. (A table is used here not to arrange data, but to design page layout.) In order to do so, you should be familiar with the properties and operations of tables that could help design page layout e.g. merging and splitting cells.

\subsection{Areas to be developed in years $7-8$}

Informatics as a subject should be practice-oriented, teachable, 
learnable, accountable and what is more, interesting if possible!

The aim is to realize that we are surrounded by computer applications. Documents are prepared to provide information, to illustrate and to let things be seen. Text-graphic or text-table documents can also appear. You can set an aim to typify applications (e.g. invitation, letters and posters), and to develop the creative skills of students related to needs lists.

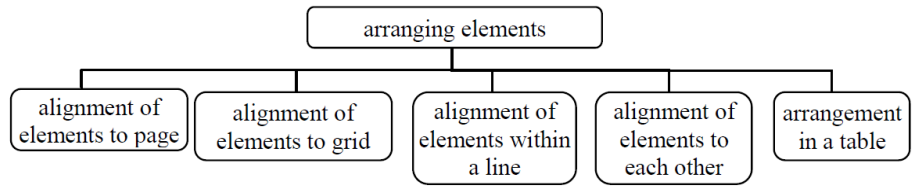

Figure 10. Arranging elements in years 7-8

In some graphic application systems the concept of lattice was introduced in order to help place elements, with the help of which you actually lay a lattice on the page, thus helping the placement of elements - either by sight or by placing the items only in lattice points.

At this level alignment within a line can be done by using tabs.

A novel method of arranging elements is listing them in space and time, and structuring longer documents into chapters and subchapters with titles, subheadings and dividing lines and line ornaments.

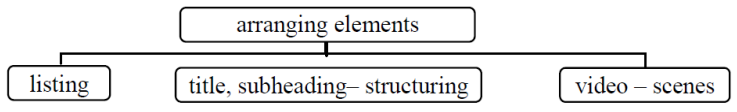

Figure 11. Arranging elements of a document in years 7-8

At this level text documents come to the front, into which students should often embed figures or sometimes even tables. Other possible tasks include illustrating myths and legends with pictures, preparing school newspapers, summer camp schedules, class schedule, timetables, business cards and calls for school events, their schedules and results. Before making text documents it is worth talking about the aesthetics of a text, its typography (patch effect, page setup, separating units and the role of highlighting).

A table should first appear in text documents. Then building upon this, you can introduce number tables. Data in the number tables should be illustrated with diagrams before doing any computing activities. 
A table is basically structured as a lattice with the same type of data in its rows and columns. Besides ordinal numbers, you can assign identifiers and labels to rows and columns. Column identifiers are placed in the column header, which is often the first line, while row identifiers are placed in the row header, which is often the first or the first and last columns).

If setting the properties (e.g. colour) of the elements of a table, you will have a very useful highlighting opportunity; for example, in a calendar feast days can be marked red. To the columns and rows of the table, there can be assigned so-called totals such as number of items, sum, average or maximum), which are calculated from rows and columns, respectively.

The format of numerical data in the cells substantive aspects can also prevail. In general, it is typical to use General and Number setting, Currency and Accounting format categories are only important for reasons of convenience, Percentage format is used for expressing ratios, whereas Scientific category can prove useful when you need to display numbers of various orders of magnitude in mathematics and science exercises. Date and Time formats actually store a value as a whole or a fraction of a real number. In addition to these basic cases, there are several opportunities to apply Custom format (e.g. editing measures, layouts, colouring depending on the number being positive or negative, customized inscriptions etc.).

\begin{tabular}{|c|c|c|c|}
\cline { 3 - 3 } \multicolumn{1}{c|}{} & \multicolumn{2}{c|}{ incorporating elements in a table } \\
\hline rows & columns & cells & row headers \\
column headers & totals \\
\hline
\end{tabular}

Figure 12. Table-like elements in years $7-8$

By modifying the properties of relevant table elements, you can emphasize table elements and their logical relationship.

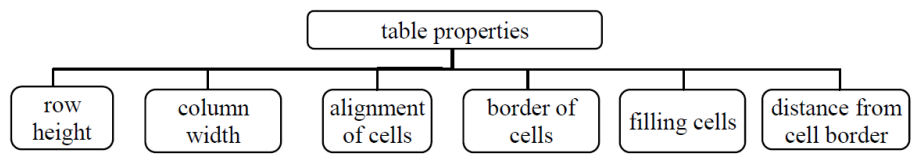

Figure 13. Properties of table-like elements in years 7-8

It is already this stage that you can introduce columns (e.g. when preparing a school newspaper mentioned above), since they are technically easy to use. You 
can do so even if the concept (i.e. section) necessary to fully understand will be taught and discussed in details only later.

The spreadsheet allows you to fill with sequences (single numbering, arithmetic sequences, geometric sequences and date sequences).

If a value is calculated from other values in a text document (a feature built in several word processors), the calculated value will not change automatically when the values are changed. However, if in a spreadsheet you use a formula containing references to other cells, for instance, the value of the formula changes together with the modified values in the cells.

The same situation may occur in numbering, as well, but in this case it is the spreadsheet that is more problematic (e.g. if you write serial numbers 1, 2, 3 ... in rows one below the other and then you delete some rows - unlike in word processors - the numbering will not recover by itself).

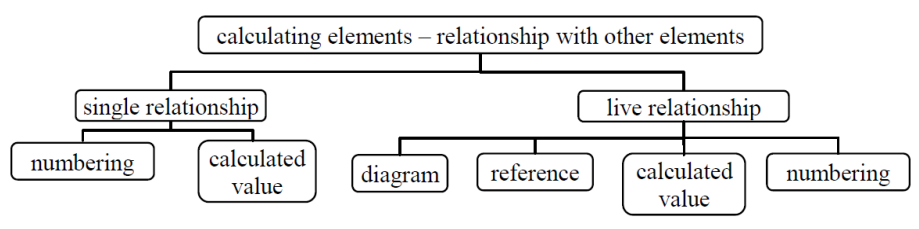

Figure 14. Calculated elements in year 7-8

At this level you could introduce searching in public information systems (exercise banks - e.g. SDT, cultural programmes, public transport timetables). Students should be able to retrieve and process information from data-bases.

Using text and graphical documents, students are required to prepare electronic bulletin boards and shop window presentations. The presentation always consists of more than one page. Obviously, concepts related to multiple-page documents such as header, footer and page number do not first appear in purely text documents, but - naturally - in multiple-page documents such as presentations.

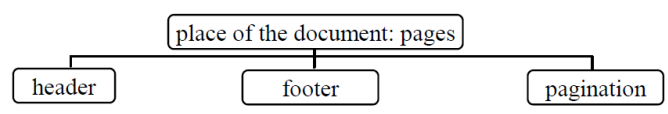

Figure 15. Pages in year 7-8 


\subsection{Areas to be developed in years $9-10$}

"Do good and well! That is the secret." (Ferenc Kazinczy)

At this level our basic aim is to make students create, print, store and repair documents, tables and databases that are related to their school and home life as well as their interests. A significant part of the written material here is a text such as a letter, a composition or a test-paper. Therefore, now it is practical to start properly dealing with multiple-page text documents.

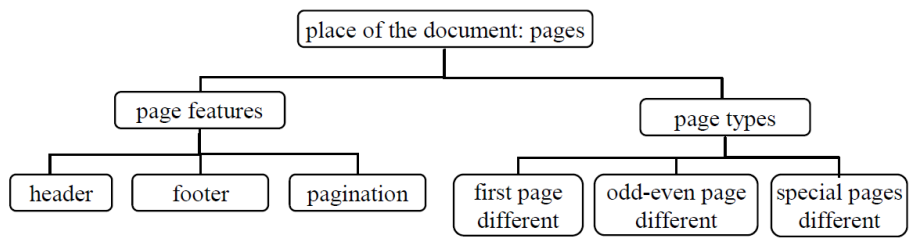

Figure 16. Pages in year 9-10

It is the stage when it is worth completing the introduction of features related to the page as a logical formatting unit (page borders, orientation, columns, margins, vertical alignment etc.). The concept of the section in word-processing can, of course, be linked to the concept of the chapter in text documents. In this case the header or footer can obtain a new function: they identify chapters with chapter-dependent headers or footers.

When preparing presentations, "special pages" include slide templates, which can be used to distinguish the style of irregularly laid pages from others. At this level it is definitely worth studying styles, slide templates, style sheets i.e. typification of document elements.

In terms of web pages there appear references i.e. links, which direct the reader to other items on the same webpage, or to another webpage of the same site or even to external websites. In special cases, the links point to files that can be opened or downloaded. As for presentations, you first of all use links when you might want to access the slides in any order (non-linear presentations). The features learnt at webpages are also available here: attached media files and URLs.

Links also have an important role in advanced and sophisticated text editing. If a document is printed, its real value is greatly increased by the presence of a table of contents, an index, a list of figures and footnotes. As for electronic publishing (eg .pdf format), "clickable links" will allow the reader to efficiently 
use the document. Links to other pages and a table of contents are common features in presentations and webpages, as well; what is more, there are websites specialized in "tables of contents" (e.g. startlap.hu).

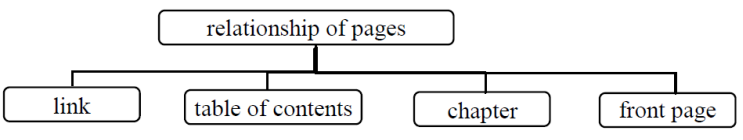

Figure 17. Relationship of pages in years 9-10

It is worth mentioning the possibilities of applying GIS, inserting maps and adding data. To do this - and many other - tasks, users may need to assign objects to one another and to fix them.

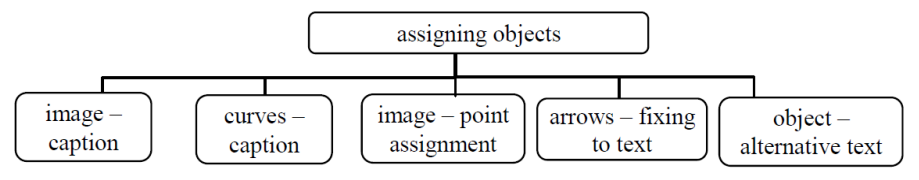

Figure 18. Assigning objects to each other in years 9-10

There are various ways to link objects to each other: just think of film subtitling, reading texts aloud, or instead of displaying videos or images, displaying the texts that describe them.

Figures and texts such as program codes are often accompanied by explanations, which must be clearly separated from the rest of the document. To do so, you can, of course, use footnotes, but there is an excellent feature which allows you to put the explanation in a special object from which an arrow points to the part of the document explained.

Naturally, students can create captions in the 5 th grade when they divide a page into parts by a table or when they insert a text below an image in each cell. The image and the caption seem to belong together there, but when you move the image, the caption will not automatically follow it the new location. There might be more complex problems, as well.

If you take a GIS map, for instance, you can extract certain pixels, to which you can assign a caption. In addition, if on the interactive map you point with the mouse to this pixel, you can display additional information.

Tables can be further structured as shown below: while the one on the lefthand side has a simple grid layout, the one on the right shows a more complex structure with merging or splitting cells. 


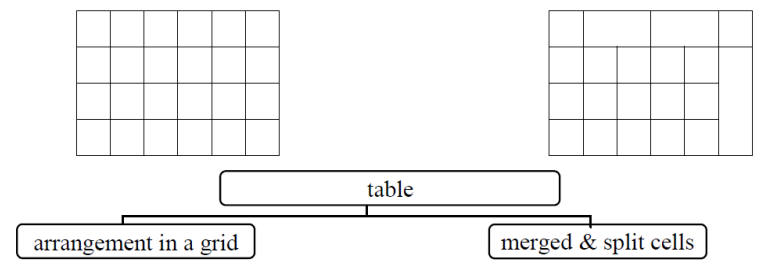

Figure 19. Types of tables in years 9-10

Regarding spreadsheets, live relationships mentioned at the previous age group do not only appear when calculating new elements, but also when the properties of elements are set. When applying conditional formatting, the format of a cell does not only depend on its value, but also on the results of the formulas containing references to other.

When students see a spreadsheet for the first time, they realize that a workbook contains several worksheets, so the flexible mechanism ensures that a file can contain several tables.

The student must be able to retrieve information from databases, process and aesthetically display them! Concerning database management, the document as a concept can be divided into two parts: a world of forms and reports. A report often appears as a listing, where numbering and calculation is a single link with the values in the database, and since it tends to be a multiple-page text document, it carries all of its features. The form, including the web form is a living link between the text document to be filled and the database in the background.

It is where you have the chance to expand the colour setting options by refining the colour model.

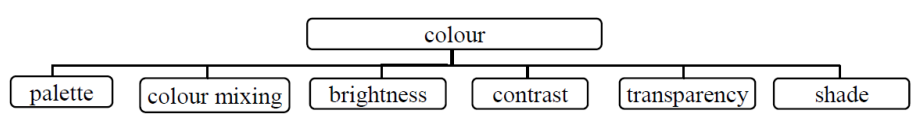

Figure 20. Colour properties for years 9-10

Using text and graphical documents, students can create electronic bulletin boards and information boards. They cannot only watch at them, but they can modify the time and order of the appearance of the pages.

We may need a new arrangement of elements in space: 


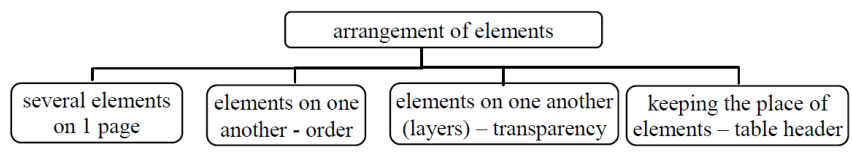

Figure 21. Arranging elements in years 9-10

and in time:

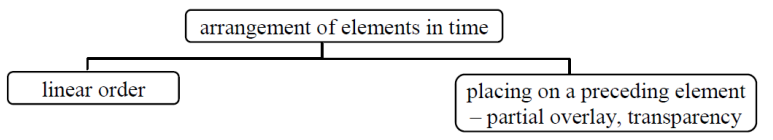

Figure 22. Arranging elements in years 9-10

A photo album or a video album - the latter is a kind of photo album, because basically, you see the first frames and captions of a video in a photo album-like way - is the simplest case of arranging several items on a page. The purport of both is to place the individual elements side by side (or above each other, or in a table-like configuration) without overlaying. As for montages and many other applications, you do not prohibit the individual elements to overlay, i.e. you can speak about the order of the items, or perhaps about transition overlays.

A layer is a shapeable and formattable unit of an image. When creating the image, it is recommended to use a separate layer for each element to be edited, transformed or repaired by itself. It also allows you to import standard elements of the previous page and only draw the new ones when creating a multiple image sequence. In general, there are plenty of opportunities of how and in what order to arrange differently transparent layers on one another. [4]

In the real world, the size of a table does not always correspond to the available page size. In a simple case it means that the table contains too many lines, and it stretches over several consecutive pages. In this case, it is advisable to fix those rows of the table - usually the head rows - that you want to see displayed on each page. It is more complicated if the table is too wide to fit one page.

Now students can be taught how to implements document types i.e. which function of which tool to use. It may include many things from animated parts of presentations to editing audio files or videos.

Regarding project work, there may arise that a document can be edited by several people (document sharing). Or a text document can be commented by its author or even by other people. There is new demand related to the set 
of documents of a project to apply a standard image and its effective and safe management (templates, styles and style sheets of websites).

Mail merge is a good example of the necessity to use different types of documents together: a text document is joined with another text document, a spreadsheet or a database. This topic should be discussed as soon as possible because it is a must, an inevitable task of the Word Processing module at ECDL.

At art schools or in connection with web design there may appear threedimensional geometric shapes - maybe for the next age group [2]:

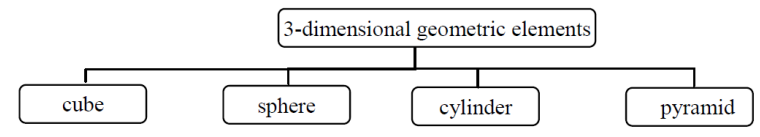

Figure 23. 3-dimensional geometric elements in years 9-10

5. Why can the identification of key concepts play an important role in planning the teaching process?

"When designing the knowledge to be acquired in a field of science or in a subject, it is essential to see the wood for the trees. We need to be aware of which of the many elements of knowledge or concepts to be learned are really important. A possible way of weighing the content is to try and identify the key concepts for a field of science first. If it is done, you should select those that must be taught in primary and secondary education by all means." [8]

In the field of informatics we define topics, draft the ICT competences to be developed, and construct the general key concepts of informatics. Further research could be done into harmonizing these three areas and into their application in curriculum design. A question could be asked in connection to the issue discussed in this article: how do ICT key concepts (in this case, the concept of document) affect the grouping or structuring ICT topics? [13]

On the basis of the above mentioned, it can be concluded that it is impossible to devise scientifically grounded and valid curricula without a thorough knowledge of the system and structure of key concepts.

\section{References}

[1] C. Borchel, L. Humbert and M. Reinertz, Design of an Informatics System to Bridge the Gap Between Using and Understanding in Informatics, Innovative Concepts for 
Teaching Informatics, Informatics in Secondary Schools: Evolution and Perspectives, Ueberreuter Verlag, Wien, 2005, 53-63.

[2] P. Boytchev, Design and Implementation of a Logo-based Computer Graphics Course, Informatics in Education 6, no. 2 (2007), 269-282.

[3] T. Brinda, H. Puhlmann and C. Schulte, Bridging ICT and CS - Educational Standards for Computer Science in Lower Secondary Education, ACM SIGCSE Bulletin - ITiCSE'09 41, no. 3 (September 2009), 288-292.

[4] I. Csatlós, Digitális képfeldolgozás tanítása a középiskolában, Neumann János Számítógép-tudományi Társaság, Budapest, 2008.

[5] P. Szlávi and L. Zsakó, Informatics as a Particular Field of Education, Teaching Mathematics and Computer Science 3, no. 1 (2005), 151-162.

[6] P. Szlávi and L. Zsakó, Informatikai kompetenciák: Algoritmikus gondolkodás, INFODIDACT 2010 - 3. Informatika Szakmódszertani Konferencia, Szombathely, Hungary, 2010. április 22-23., 2010, konferencia-CD.

[7] P. Szlávi and L. Zsakó, Az informatika általános kulcsfogalmai: adat, INFODIDACT 2011 - 4. Informatika Szakmódszertani Konferencia, Szombathely, 2011. március 31-április 1., 2011, konferencia-CD.

[8] NAT-hoz illeszkedő kulcsfogalom-rendszer, kulcskompetencia-térkép, tanulmány, (V. Vass, ed.), Nemzeti Tankönyvkiadó, Budapest, 2011.

[9] S. Voß, Informatic models in vocational training for teaching standard software, 2005, http://issep.uni-klu.ac.at/material/voss.pdf.

[10] L. Zsakó, Teaching Informatics in Hungary, The IOI'96 NewsLetter 2, 3, 4, Neumann János Számítógép-tudományi Társaság, Budapest (1995), 5-6.

[11] L. Zsakó, Fejezetek az informatika szakmódszertanából, Habilitációs értekezés, Debrecen, 2007.

[12] L. Zsakó, Z. Kátai and K. Nyakóné-Juhász, ICT methodology, Teaching Mathematics and Computer Science-Infodidact (2008), 3-24.

[13] L. Zsakó, Az informatika kulcsfogalmai: algoritmus, Informatika a felsőoktatásban 2011, (Debrecen, 2011. augusztus 24-26), Debreceni Universitas, 2011, konferencia-CD.

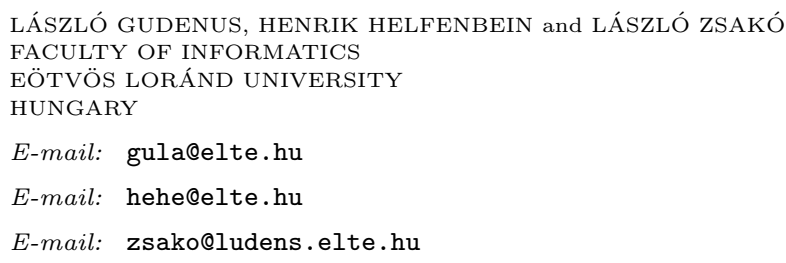

(Received September, 2013) 